\title{
Population dynamics and diversity of Bactocera species and Dichasmimorpha longicaudata, its parasitoid in correlation with abiotic factors
}

Khawar Jawad Ahmad ${ }^{1}$, Qurban Ali ${ }^{*}$, Faisal Hafeez ${ }^{1}$, Dilbar Hussain ${ }^{1}$, Asad Aslam ${ }^{1}$, Muhammad Shehzad ${ }^{2}$, Muhammad Faheem Akhtar ${ }^{1}$, Muhammad Umar Qasim ${ }^{1}$, Muhammad Zubair ${ }^{3}$, Muhammad Jawad Saleem ${ }^{1}$ and Muhammad Ahsin Ayub ${ }^{1}$

1. Entomological Research institute, Ayub Agriculture Research Institute, Faisalabad-Pakistan

2. Department of Entomology, Pir Mehar Ali Shah, Arid Agriculture University Rawalpindi-Pakistan

3. Oilseed Research Institute, Ayub Agriculture Research Institute, Faisalabad-Pakistan

*Corresponding author's email: qurban_ent@yahoo.com

Citation

Khawar Jawad Ahmad, Qurban Ali, Faisal Hafeez, Dilbar Hussain, Asad Aslam, Muhammad Shehzad, Muhammad Faheem Akhtar, Muhammad Umar Qasim, Muhammad Zubair, Muhammad Jawad Saleem and Muhammad Ahsin Ayub. Population dynamics and diversity of Bactocera species and Dichasmimorpha longicaudata, its parasitoid in correlation with abiotic factors. Pure and Applied Biology.Vol. 9, Issue 3, pp1882-1894.

http://dx.doi.org/10.19045/bspab.2020.90201

Received: 22/02/2020

Revised: $27 / 04 / 2020$

Accepted: $10 / 05 / 2020$

Online First: 19/05/2020

Abstract

Fruit flies are destructive pests and caused heavy losses in agricultural products by reducing crop production. The reported study was planned to evaluate the relationship between population dynamic of fruit flies and its parasitoid in guava orchards in relation to prevailing ecological condition. For this purpose, baited pheromone traps containing methyl eugenol with contact action Insecticides were installed in guava orchards in Faisalabad district during 2016-18. Trapped fruit flies were collected after every fortnightly interval and brought in the laboratory for identification of species. The infested guava fruits were also collected from fruit trees during the fruiting season and kept under laboratory conditions to identify and record parasitoids species as well as emerging Fruit flies. Results revealed that $B$. zonata, B. correcta and $B$. dorsata prevail around the year. However population of $B$. dorsata was more than $B$. zonata followed by $B$. correcta. Peak infestation of fruit fly was has been observed in October 2016-17 while in 2018 highest population was recorded in September. However, low population of fruit flies species had been recorded when temperature dropped $<05{ }^{\circ} \mathrm{C}$. Emergence from infested fruit predicts that $60 \%$ emergence was solely by the population of $B$. dorsata followed by B. zonata and B. correcta throughout the year. The highest number of $D$. longicaudata was recorded in July and August and also directly influenced by pupae emergence from the larvae. Highest and lowest temperature exerted more effect on population fluctuation of pest as well as its parasitoid as compared to other factors.

Keywords: Abiotic factor; Diversity; Fruit fly species; Parasitoid; Population dynamics 


\section{Introduction}

Guava (Psidium guajava) is most favorite and nutritional fruit in Asia as well as all over the world belongs to family Myrtaceae [1]. Fruit flies are most destructive pests of fruits, causing decrease in yield and deteriorating the market value. In 1907, it was first observed in Taiwan [2] but now it has been spread to Asia Pacific regions [3, 4]. It inserts the ovipositor in the fruits and lays egg inside, near fruit skin. Maggots develops inside the fruit. Latterly, maggots drill its way out after completing its period to pupate in soil and emerge as winged adult to continue the life cycle [5]. There is great taxonomic diversity in fruits fly withmore than 5000 species present all over the world [6] which not only infest the fruit but also affect the vegetables. Among all the fruit fly species Bactrocera zonata, B. correcta and $B$. dorsata are commonly found in guava orchards. Peak population of different species of fruits flies was recorded from April to august on guava and mango orchards [7] and caused 30 to $100 \%$ losses in these fruits. Fruit flies quarantine pest and caused hindrances in international trade [8].

Farmers use different techniques to control fruit fly attack. Chemicals used to control fruit fly are not encouraged due to residual effects [9]. Different environmental friendly techniques like Sterile Insect Technique (SIT) [10] pheromone traps [11] and sanitation (disposal of damage fruits) $[12,13]$ are well adopted approaches for the management of fruit flies. The scientist observed population dynamics of this pest by using different traps like Mcphail traps and correlated it with environmental conations [14].

In recent decades, increasing interest in parasitoids into integrated pest management programs has been replaced by classical biological control. This is often likely to reflect not only an increased awareness of the non-target action of insecticides on beneficial insects and human beings but also significant advancements in rearing techniques and artificial diets for rearing hosts for augmentative biological control programs [15,16]Diachasmimorpha

longicaudata Ashmead (Hymenoptera: Braconidae) is naturally available parasitioid in Pakistan and South East countries [17]. It parasitoid the larval and prepupal stages of fruit fly of genera Anastrepha, Ceratitis and Bactrocera. In Pakistan, Its parasitism rate exceeds $36 \%$ on B. Dorsalis and $44 \%$ in $B$. Zonata [18]. The objective of this studyis to evaluate the diversity and population dynamics of fruit fly species and it's parasitoid $D$. longicaudataco relation to environmental factors in Faisalabad during years 2016-18.

\section{Materials and methods}

Studies on population dynamics of fruit flies was conducted in different places of guava orchards in district Faisalabad during 201618 . The fruit fly species mainly (B. zonata, $B$. correcta and $B$. dorsata) were recorded by installation traps in guava orchards. In the selected orchards, five fruit fly traps with methyl-eugnol and contact action insecticide (Malathion@1ml/trap) (as bait)was installed at 6 feet height from the ground and $12 \mathrm{~m}$ apart from each other. The baits in traps was replaced every 24 hours. The data regarding number of fruit flies were recorded fortnightly. Collected individuals were identified up to species level. The population fluctuation of three fruit fly species $(B$. zonata, B. correcta and $B$. dorsata) were kept in consideration in this study. Infested guava fruits were collected and kept in laboratory under favorable conditionsto identify the fruit fly species and their parasitoids. The obtaining pupae from larvae were kept in Petri dishes and emerging fruit fly specie and parasitoids from pupae were recorded and identified. The metrological data was also 
obtained from crop physiology section, Ayub Agriculture Research Institute Faisalabad.

\section{Data analysis}

The mean values of pest and parasitoid population along with standard error was calculated by using statistical software (Statistix 8.1). The impact of environmental factors on the fluctuation of three species of fruit fly on individual and combined level by using Hierarchical Regression Model.

\section{Results}

Population fluctuations of fruit fly species (B. zonata, B. correcta and $B$. dorsata) during 2016-18

Population fluctuations of fruitflyspecies (B. zonata, $B$. correcta and $B$. dorsata) during 2016

Population of B. zonata, B. correcta and $B$. dosata from the orchards of Guava in District Faisalabad during 2016-2018. After experiments it is obvious that population of fruit fly correlates with the ripening of guava fruits and weather conditions. The minimum mean population (0.4/trap)of $B$. zonata, was observed in the February 2016. $B$. correcta was not observed during first fortnight of February during 2016. B. dorsata lowest peak was recorded in last weeks of January2016 with mean population of $0.2 /$ trap. The population of all three species start to increase in the last week of March during 2016with mean population of $B$. zonata, B. correcta and $B$. dosata was 1.00 , 1.00 and 2.00 per trap, respectively. However average population of $B$. zonata was 36.2/trap, B. correcta was 30.8/trap and $B$. dorsata was 39.8/trap in May. In June 2016, $B$. zonata and $B$. Correcta population increased and it reached to 36.2/trap, 20.2/trap, respectively. for but B. dorsata population declines to 33.4/trap.for July 2016 $B$. zonata counts about 25.2 however species $B$. correcta number population reduces to 28.4and $B$. dorsata increases to almost 55.4/trap. The maximum population of $B$. zonata was in August and September 56.4/trap, 55.4/trap, respectively after that its population decreased and reached to 1.00/trap in December 2016. However, $B$. correcta highest population was observed in first week of October 51.2 and it decreased in December to 0.6. B. dorsata population was highest in September 74.6/trap and lowest in mid of December 1.8/trap (Graph 1).

Population Fluctuations of Fruit fly species (B. zonata, B. correcta and $B$. dorsata) during 2017

The population of fruit flies in the year 2017 shows a slight different trend as compared to 2016. Minimum population 0.2/trap of $B$. correcta was observed in last week of January in 2017 and an increases rate was recorded in October that was 53/trap. Population level start to declines afterward reaches to 1.6/trap in November and $1.00 /$ trap in the month of December during the present year. However, B. correcta population was minimum 0.2 /trap in the last week of January. The gradual increase in population of $B$. correcta was observed in March and April that was 2.3/trap, 15/trap, respectively and finally population was maximum in first week of October. Afterward, population start to decline with decrease in temperature and population was 0.4/trap in December. B. dorsata population was higher than $B$. correcta and $B$. zonata. The least population of $B$. dorsata was recorded in February and March that was 1.00/trap and 5.6/trap. The $B$. dorsata population gradual increase was observed in the months of April 30.8/trap and May 45.2/trap. Maximum population of B. dorsata was recorded the month of September 81.8/trap in 2017. After that gradual decrease in population was recorded in October 57.8 and finally lowest population was in December 2.4/trap (Graph 2) 


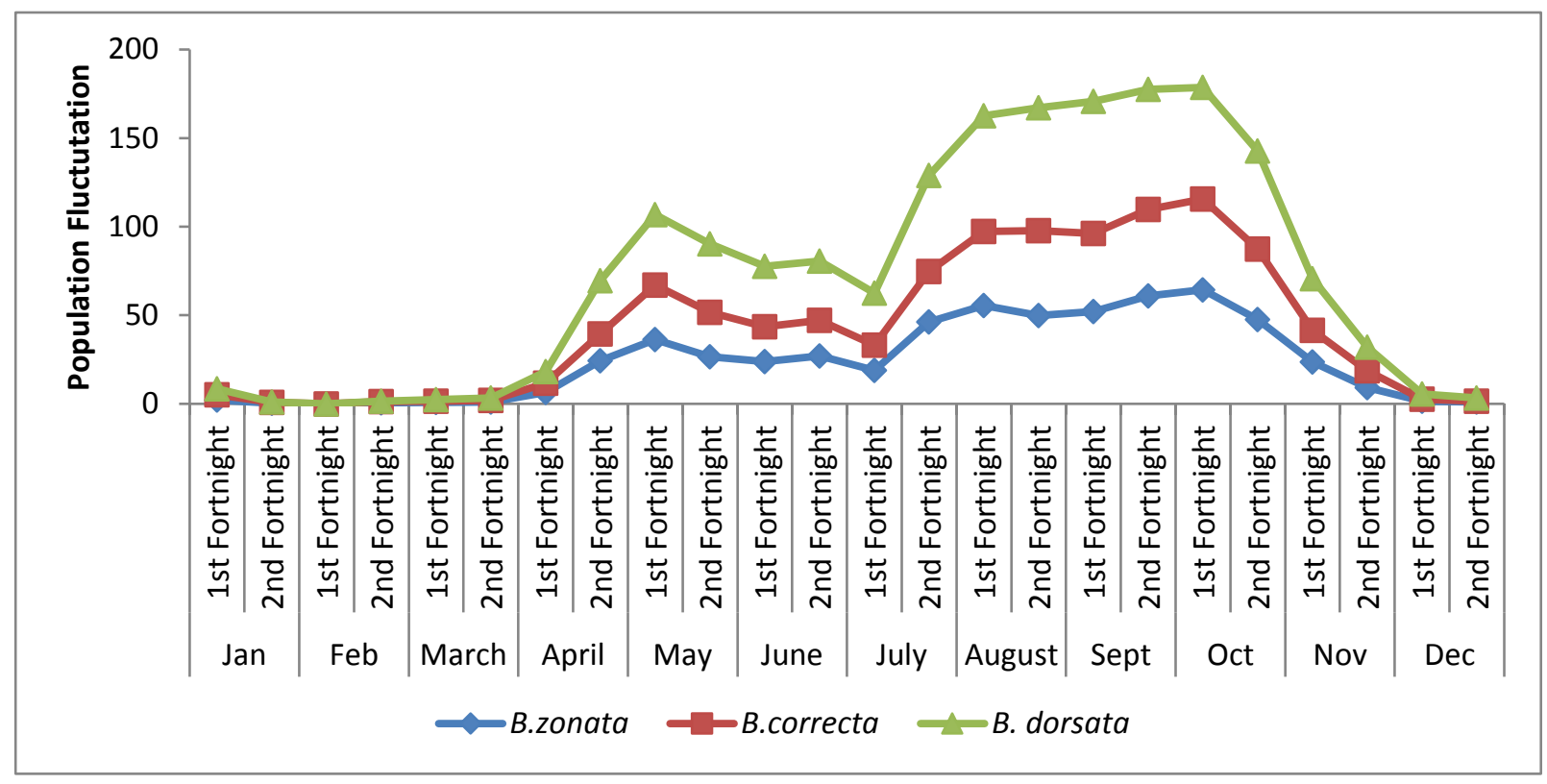

Graph 1. Population dynamic of three fruit flies species during year 2016

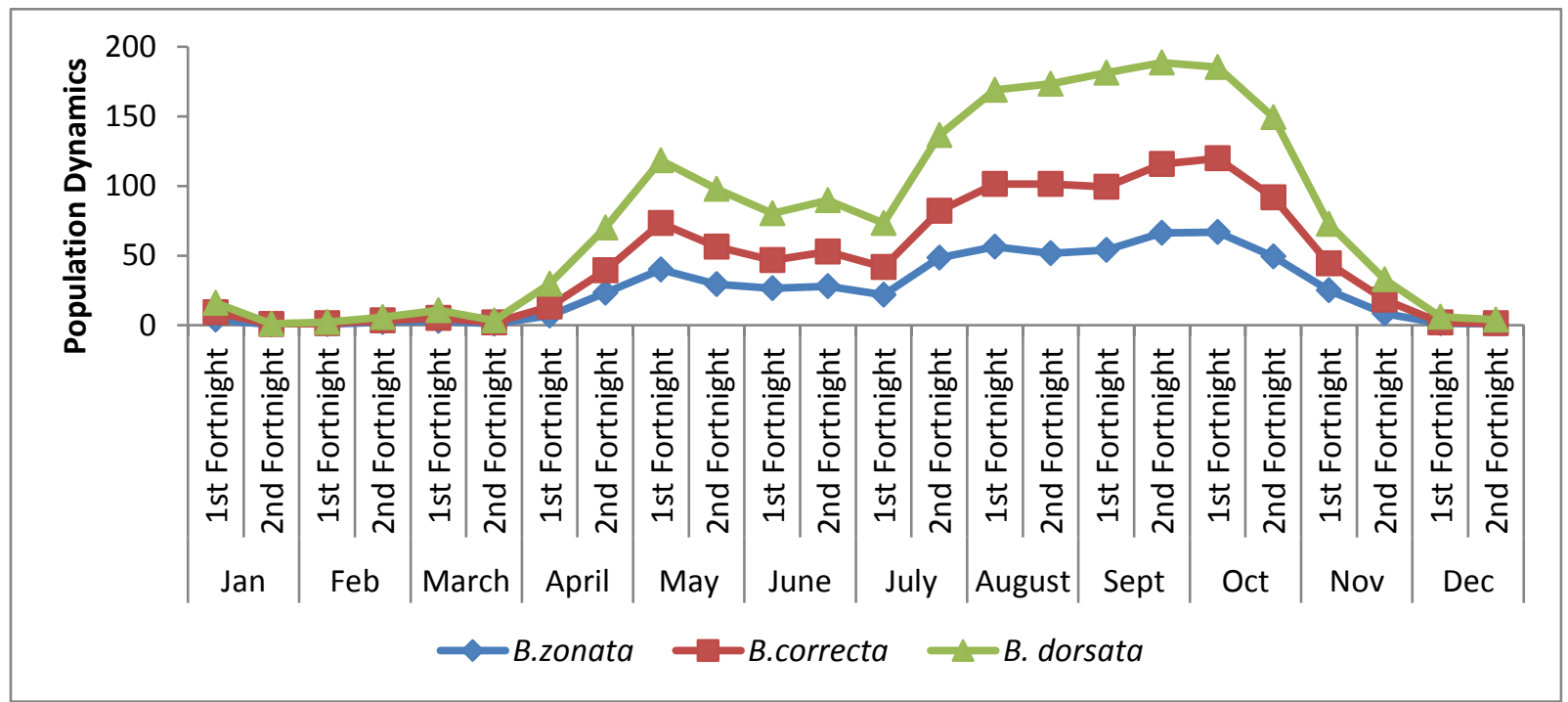

Graph 2. Population dynamic of three fruit flies species during year 2017

Population fluctuations of fruit fly species (B. zonata, $B$. correcta and $B$. dorsata) during 2018

During 2018, there was zero population of $B$. zonata in February. After February, Population level gradually start to increase and there was 2.00/trap in March and 47.2/trap in May, highest population was recorded in August and September that was55.4/trap and 74.8/trap, respectively. After September, population level start to decline and finally, population of B. correcta was highly reduced in last week of January 2018. The population rises as the temperature enhance. The tremendously enhanced population was recorded in August 51/trap and September 57/trap and highest peak population was observed in first week of October 57.4/trap. Lowest level of population was recorded in December that was 0.6/trap. B. dorsata population was lowest in February 0.6/trap and March 8.2/trap. Gradual increase 
in $B$. dorsata population was recorded in April 26.2/trap, May 65/trap, June 72.4/trap and peak level of population was recorded in September 85.4/trap. After that population gradually start to decrease from October and attained its lowest population level in December 0.6/trap (Graph 3).

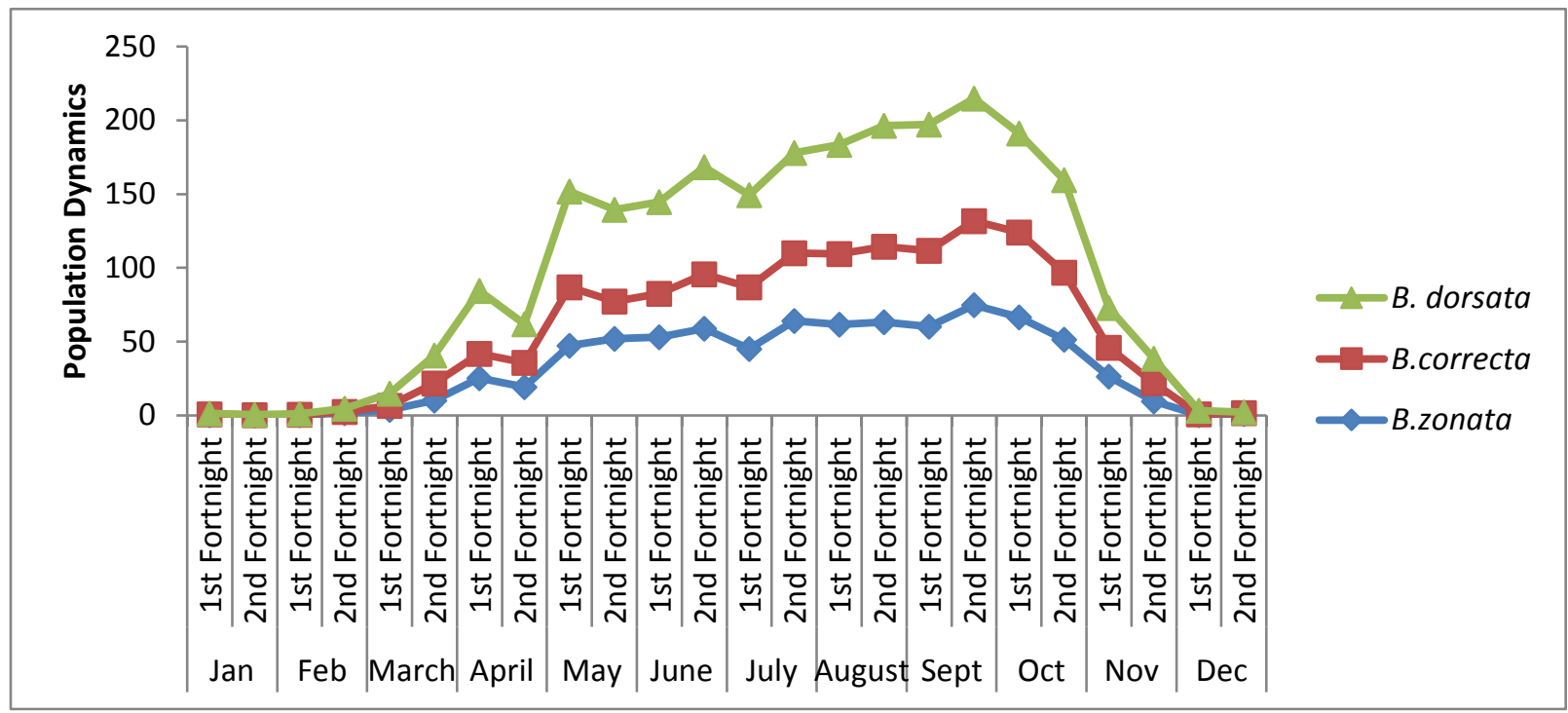

Graph 3. Population dynamic of three fruitflies species during year 2018

Impact of weather parameters on population fluctuation of fruit fly species

Weather factors significantly affect the fluctuation of all species of fruit fly in this experiment. The impact of weather conditions during 2016 revealed that maximum temperature was exerted $46.53 \%$ role in B.zonata population fluctuation which highest as compared to other climatic factors. High temperature showed highly significant positive impact on population while minimum relative humidity, temperature and rain fall during 2016 played $11.16 \%, 6.79$ and $0.01 \%$ role respectively. High temperature impacted $64.44 \%$ role for the population variation of B.zonata during 2017 and similarly it played $64.44 \%$ role during 2018. Low temperature exerted more role $(10.78 \%)$ than relative humidity $(5.00 \%)$ during 2018. Low temperature and humidity positively significantly affect the variation of B.zonata population (Table 1).

The $B$. correcta showed almost similar relation with climatic conditions. High temperature had participated highest $45.1 \%$ role and showed highly significant impact on population fluctuation on B. correcta during 2016 (Table 2). The relative humidity had more role $(10.57 \%)$ as compared to low temperature (5.66\% and 7.49\%) during 201617 while low temperature participated $(11.73 \%)$ more than relative humidity (9.37\%) during 2018 (Table 2). High temperature exerted positive significant impact $(54.4 \%)$ on the population of B.corresta in 2018 (Table 2).

In the case of $B$. dorsata, more population fluctuation was observed as compared to B.zonata and B.corecta. Similarly, high temperature showed highest role $(51.37 \%)$ during 2016 on the pest population fluctuation as compared to other weather factors (Table 3). The impact of maximum temperature was significant positive. The minimum temperature had $9.11 \%$ and $12.67 \%$ during 2017 and 2018 which higher than relative humidity $(8.11 \%$ and $3.52 \%)$ whereas relative humidity participated more 
$(10.87 \%)$ than minimum temperature (8.34\%) during 2016. Maximums temperature had positive significant impact
$46.6 \%$ and $64.4 \%$ roles during 2017 and 2018 respectively (Table 3 ).

Table 1. Regression analysis (Hierarchical regression model) of population fluctuation of Bactrocera zonata with weather factor along with coefficient of determination for 2016-2018

\begin{tabular}{|c|c|c|}
\hline Year & Regression equation & Impact \\
\hline 2016 & $\begin{array}{c}\mathrm{Y}^{* *}=-43.09^{*}+2.087 \mathrm{X}_{1} * * \\
\mathrm{Y}^{* *}=-11.11-0.12 \mathrm{X}_{1}+2.12 \mathrm{X}_{2} \\
\mathrm{Y}^{*}=-152.348^{* *}+3.29878 \mathrm{X}_{1}+3.29878 \mathrm{X}_{2}+1.11428 \mathrm{X}_{3} * \\
\mathrm{Y}^{* *}=-152.553 *+3.28627 \mathrm{X}_{1}+0.12103 \mathrm{X}_{2}+1.11879 \mathrm{X}_{3}{ }^{*}-0.02998 \mathrm{X}_{4}\end{array}$ & $\begin{array}{c}46.53 \\
6.79 \\
11.16 \\
0.01\end{array}$ \\
\hline 2017 & $\begin{array}{c}\mathrm{Y}^{* *}=-41.57 *+2.108 \mathrm{X}_{1} * * \\
\mathrm{Y}^{* *}=-12.61+0.119 \mathrm{X}_{1}+1.93 \mathrm{X}_{2}{ }^{*} \\
\mathrm{Y}^{* *}=-123.56^{*}+2.67 \mathrm{X}_{1}+0.51 \mathrm{X}_{2}+0.90 \mathrm{X}_{3} * \\
\mathrm{Y}^{* *}=-120.51^{*}+2.18 \mathrm{X}_{1}+1.34 \mathrm{X}_{2}+0.93 \mathrm{X}_{3}{ }^{*}-0.81 \mathrm{X}_{4}\end{array}$ & $\begin{array}{c}46.68 \\
7.12 \\
9.53 \\
5.5\end{array}$ \\
\hline 2018 & $\begin{array}{c}\mathrm{Y}^{* *}=-58.76^{* *}+3.92 \mathrm{X}_{1}^{* *} \\
\mathrm{Y}^{* *}=-29.34+0.74 \mathrm{X}_{1}+2.16 \mathrm{X}_{2}^{* *} \\
\mathrm{Y}^{* *}=-91.02 *+1.51 \mathrm{X}_{1}+1.92 \mathrm{X}_{2}^{* *}+0.69 \mathrm{X}_{3}^{*} \\
\mathrm{Y}^{* *}=-78.97 *+1.37 \mathrm{X}_{1}+1.81 \mathrm{X}_{2} *+0.57 \mathrm{X}_{3}+0.20 \mathrm{X}_{4}\end{array}$ & $\begin{array}{l}64.44 \\
10.78 \\
5.00 \\
1.44\end{array}$ \\
\hline
\end{tabular}

Where, Y=Fruitfly (Bactrocerazonata) Population; X1= Fortnightly Maximum temperature; X2= Fortnightly Minimum temperature; X3= Average Fortnightlyrelative humidity; X4= Average Fortnightly rainfall $(\mathrm{mm}) ; *=$ Significant at $\mathrm{P} \leq 0.05 ; * *=$ HighlySignificant at $\mathrm{P} \leq 0.01$

Table 2. Regression analysis (Hierarchical regression model) of population fluctuation of Bactrocera correcta with weather factor along with coefficient of determination for 20162018

\begin{tabular}{|c|c|c|}
\hline Year & Regression Equation & Impact \\
\hline 2016 & $\begin{array}{c}\mathrm{Y}^{* *}=-34.32 * *+1.67 \mathrm{X}_{1} * * \\
\mathrm{Y}^{* *}=-10.61+0.025 \mathrm{X}_{1}+1.57 \mathrm{X}_{2} \\
\mathrm{Y}^{* *}=-122.258^{*}+2.73 \mathrm{X}_{1}-0.030 \mathrm{X}_{2}+0.881 \mathrm{X}_{3} * \\
\mathrm{Y}^{* *}=-123.35^{*}+2.67 \mathrm{X}_{1}+0.123 \mathrm{X}_{2}+0.91 \mathrm{X}_{3}{ }^{*}-0.67 \mathrm{X}_{4}\end{array}$ & $\begin{array}{c}45.1 \\
5.66 \\
10.57 \\
0.43\end{array}$ \\
\hline 2017 & $\begin{array}{c}\mathrm{Y}^{* *}=-33.10^{*}+1.70 \mathrm{X}_{1} * * \\
\mathrm{Y}^{* *}=-9.06+0.048 \mathrm{X}_{1}+1.60 \mathrm{X}_{2} \\
\mathrm{Y}^{* *}=-96.40 *+2.051 \mathrm{X}_{1}+0.48 \mathrm{X}_{2}+0.71 \mathrm{X}_{3} * \\
\mathrm{Y}^{* *}=-93.88^{*}+1.66 \mathrm{X}_{1}+1.75 \mathrm{X}_{2}+0.74 \mathrm{X}_{3}{ }^{*}-0.677 \mathrm{X}_{4}\end{array}$ & $\begin{array}{l}46.26 \\
7.49 \\
8.99 \\
5.73\end{array}$ \\
\hline 2018 & $\begin{array}{c}\mathrm{Y}^{* *}=-39.78^{* *}+2.07 \mathrm{X}_{1}^{* * *} \\
\mathrm{Y}^{* *}=-16.06+0.31 \mathrm{X}_{1}+1.74 \mathrm{X}_{2} * \\
\mathrm{Y}^{* *}=-81.32^{* *}+1.13 \mathrm{X}_{1}+1.48 \mathrm{X}_{2}{ }^{*}+0.73 \mathrm{X}_{3} * \\
\mathrm{Y}^{* *}=-74.90^{*}+1.06 \mathrm{X}_{1}+1.43 \mathrm{X}_{2}{ }^{*}+0.66 \mathrm{X}_{3} *+0.11 \mathrm{X}_{4}\end{array}$ & $\begin{array}{c}54.4 \\
11.73 \\
9.37 \\
0.68\end{array}$ \\
\hline
\end{tabular}

Where, Y=Fruitfly Population; X1= Fortnightly Maximum temperature; X2= Fortnightly Minimum temperature; X3= Average Fortnightlyrelative humidity; X4= Average Fortnightly rainfall $(\mathrm{mm}) ; *=$ Significant at $\mathrm{P} \leq 0.05 ; * *=\mathrm{Highly}$ Significant at $\mathrm{P} \leq 0.01$ 
Table 3.Regression analysis (Hierarchical regression model) of population fluctuation ofBactrocera dorsata with weather factor along with coefficient of determination for 20162018

\begin{tabular}{|c|c|c|}
\hline Year & Regression equation & Impact \\
\hline 2016 & $\begin{array}{c}\mathrm{Y}^{* *}=-54.01 * *+2.60 \mathrm{X}_{1} * * \\
\mathrm{Y}^{* *}=-11.97-0.31 \mathrm{X}_{1}+2.79 \mathrm{X}_{2} * \\
\mathrm{Y}^{* *}=-177.31 *+3.70 \mathrm{X}_{1}+0.41 \mathrm{X}_{2}+1.30 \mathrm{X}_{3} * \\
\mathrm{Y}^{* *}=-179.448^{*}+3.57 \mathrm{X}_{1}+0.71 \mathrm{X}_{2}+1.35 \mathrm{X}_{3}{ }^{*}-0.311 \mathrm{X}_{4}\end{array}$ & $\begin{array}{c}51.37 \\
8.34 \\
10.87 \\
0.75\end{array}$ \\
\hline 2017 & $\begin{array}{c}\mathrm{Y}^{* *}=-49.66^{*}+2.57 \mathrm{X}_{1} * * \\
\mathrm{Y}^{* *}=-11.28-0.064 \mathrm{X}_{1}+2.56 \mathrm{X}_{2} * \\
\mathrm{Y}^{* *}=-136.44^{*}+2.80 \mathrm{X}_{1}+0.95 \mathrm{X}_{3}+1.02 \mathrm{X}_{4} * \\
\mathrm{Y}^{* *}=-133.19^{*}+2.29 \mathrm{X}_{1}+1.84 \mathrm{X}_{2}+1.05 \mathrm{X}_{3}{ }^{*}-0.87 \mathrm{X}_{4}\end{array}$ & $\begin{array}{l}50.49 \\
9.11 \\
8.81 \\
4.52 \\
\end{array}$ \\
\hline 2018 & $\begin{array}{c}\mathrm{Y}^{* *}=-71.14 * *+3.56 \mathrm{X}_{1} * * \\
\mathrm{Y}^{* *}=-33.60^{*}+0.79 \mathrm{X}_{1}+2.76 \mathrm{X}_{2} * * \\
\mathrm{Y}^{* *}=-94.47 * *+1.55 \mathrm{X}_{1}+2.522 \mathrm{X}_{2} *+0.68 \mathrm{X}_{3}^{*} \\
\mathrm{Y}^{* *}=-85.99 *+1.45 \mathrm{X}_{1}+2.44 \mathrm{X}_{2} *+0.59 \mathrm{X}_{3}+0.144 \mathrm{X}_{4}\end{array}$ & $\begin{array}{l}69.68 \\
12.67 \\
3.52 \\
0.51\end{array}$ \\
\hline
\end{tabular}

Where, $\mathrm{Y}=$ Fruitfly Population; $\mathrm{X}_{1}=$ Fortnightly Maximum Temperature; $\mathrm{X}_{2}=$ Fortnightly Minimum Temperature; $\mathrm{X}_{3}=$ Average Fortnightly Relative Humidity; $\mathrm{X}_{4}=$ Average Fortnightly Rainfall $(\mathrm{Mm}) ; *=$ Significant At $\mathrm{P} \leq 0.05 ; * *=$ Highly Significant At $\mathrm{P} \leq 0.01$

Emergence of different fruitfly species and its parasitoid under laboratory conditions Results showed that there is no pupation until middle of March for all species of fruit flies during 2016 (Graph 4).However, The number pupae increased till October after which pupation decrease and becomes zero in the month of December. Relationship between parasitoid emergence and number of pupae showed that they have positive relationship with each other (Graph 5). Number of pupae increased as the number of parasitoid emerged until October. Highest number of parasitoid emergences were recorded in July and August during 2016. Results showed that there a positive relationship between parasitoid emergence with number of pupae in 2017 (Graph 6) of pupae. Highest number of emerged parasitoids was recorded in July and August during 2017. Comparative analysis of population dynamic of three fruitflies species are depicted in(Graph 7), it showed that the population of all fruit fly species was higher in 2017 than from the previous year and same pattern was also recorded for number of pupae. Population dynamic of all three fruit flies species and number of pupae in 2018 is almost similar as that of during 2017 and positive linear relationship was recorded (Graph 8). Results (Graph 9) showed a positive relationship between parasitoid emergence and number of pupae. As the number of pupae increases up to October the no of parasitoid emergence also increases. Maximum no of parasitoid emerged were observed in July and August during 2018. 


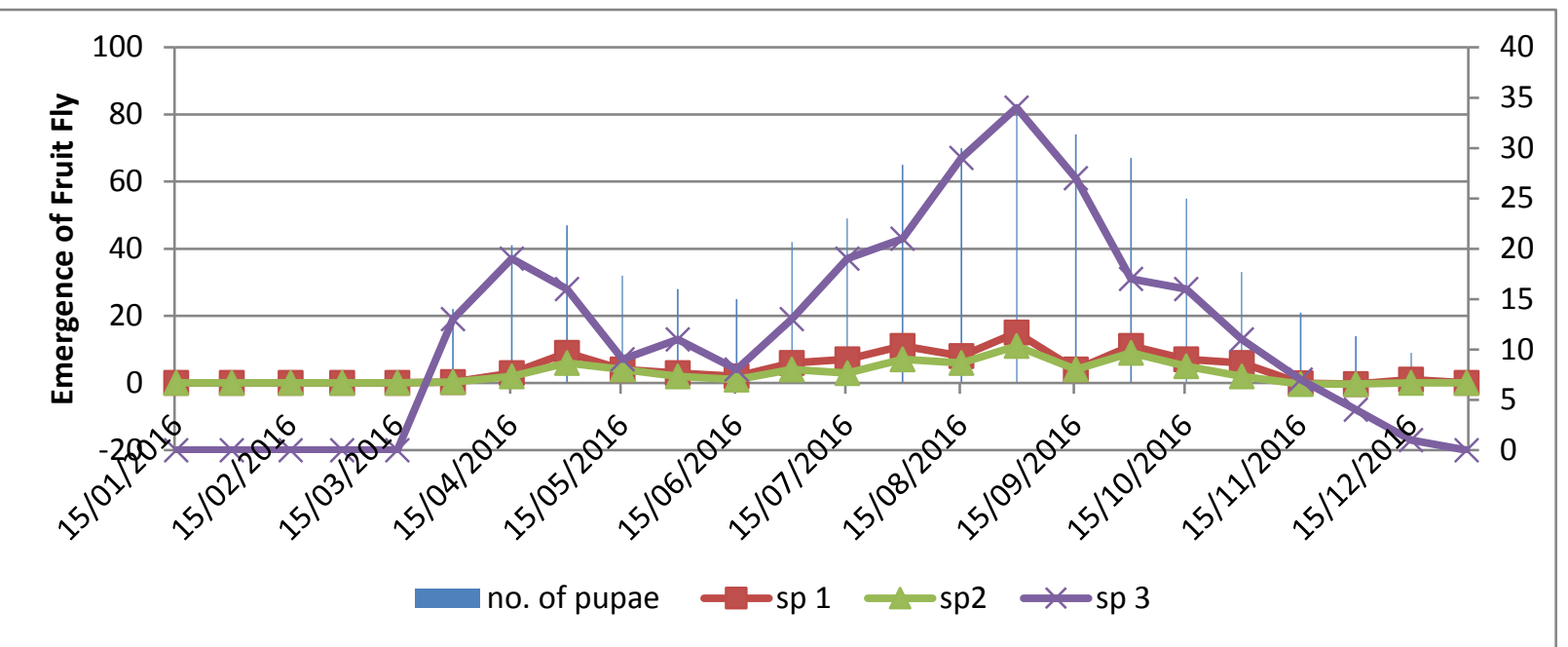

Graph 4. Emergence of fruit fly species under laboratory conditions during 2016

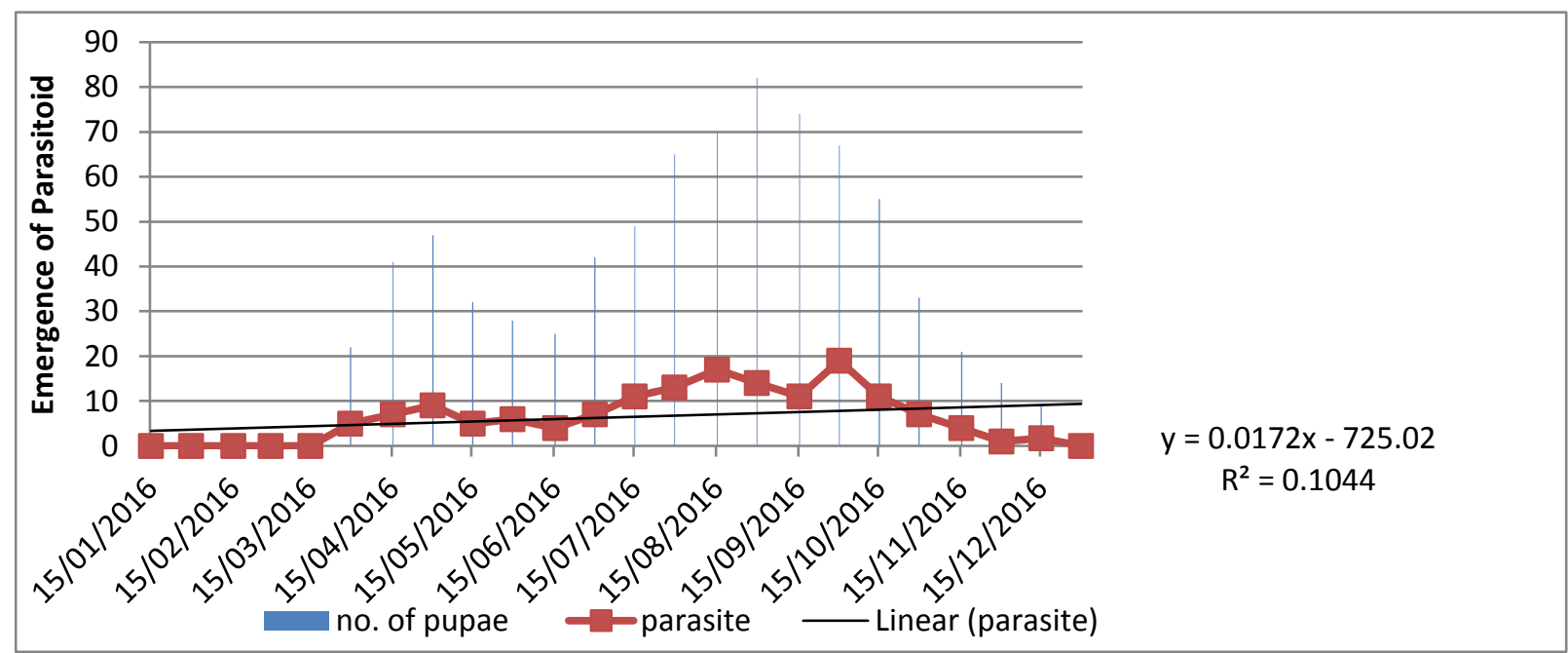

Graph 5.Emergence of parasitoids ( $D$. longicaudata) under Laboratory conditions during2016

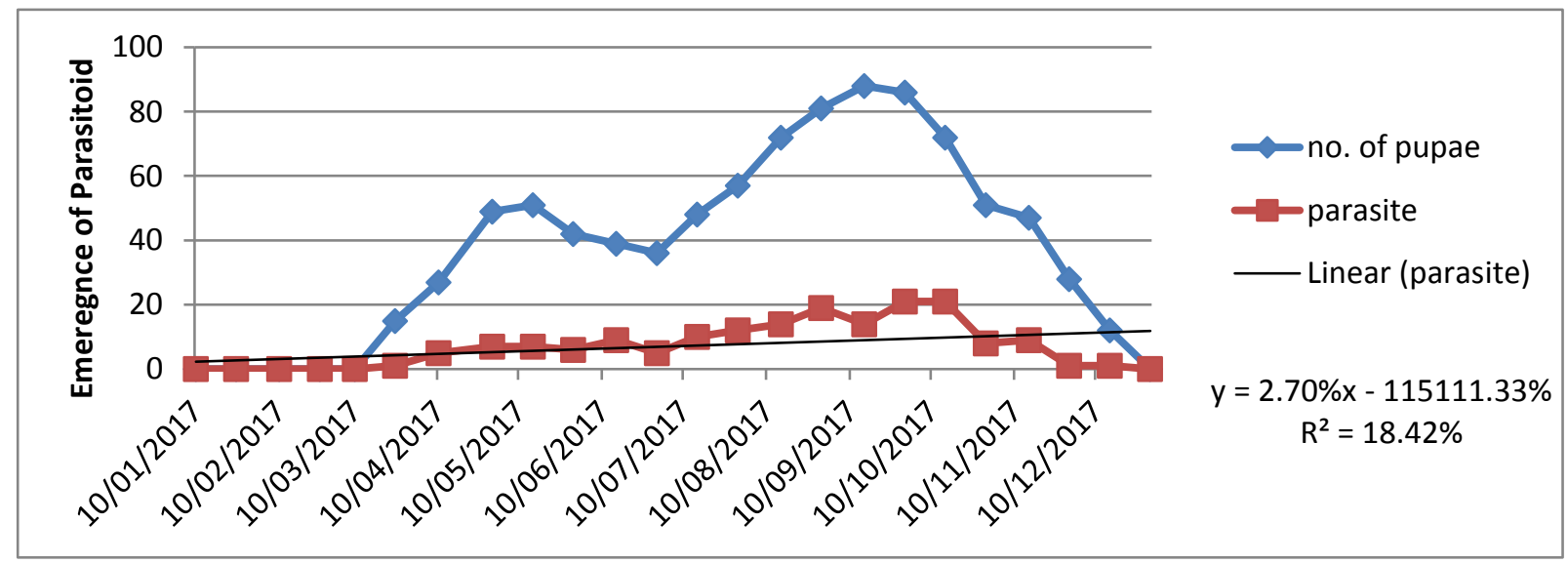

Graph 6. Emergence of Parasitoids (Dichasmimorpha Longicaudata) Under LaboratoryConditions during 2017 


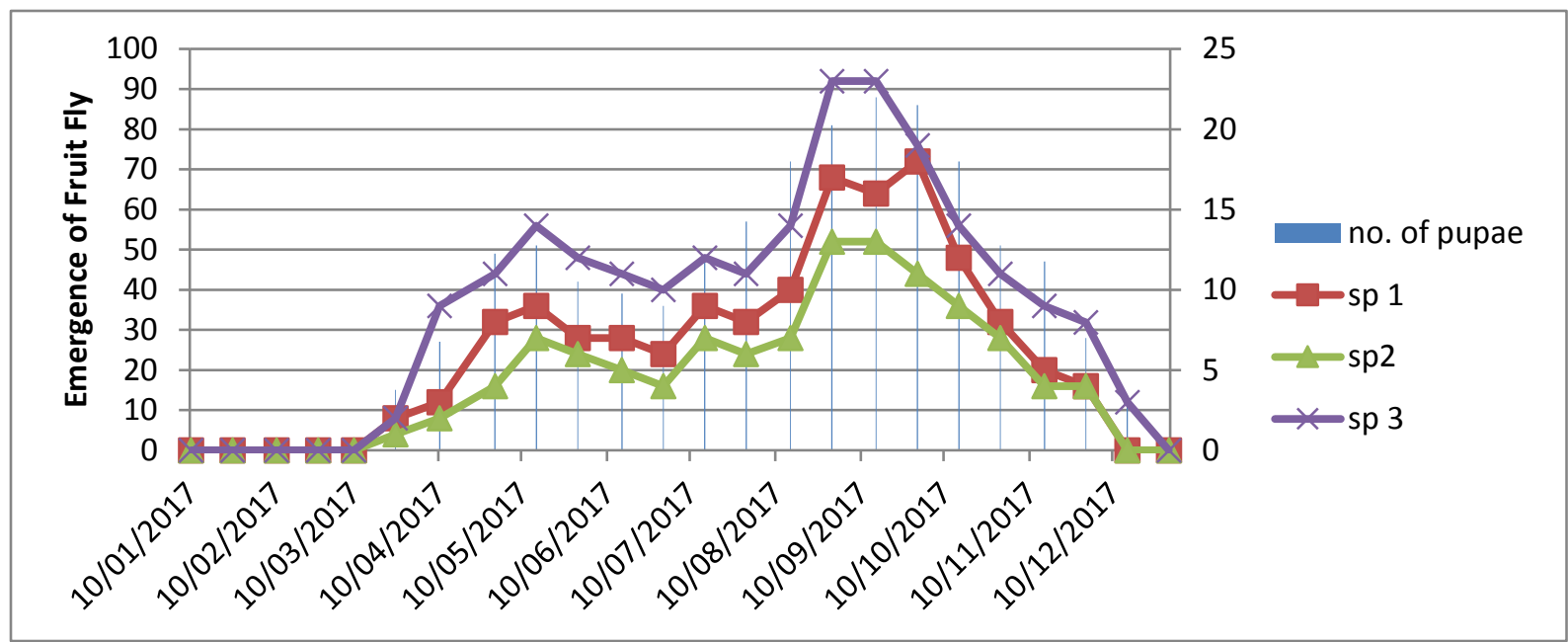

Graph 7.Emergence of different fruitfly species under Laboratory conditions during 2017

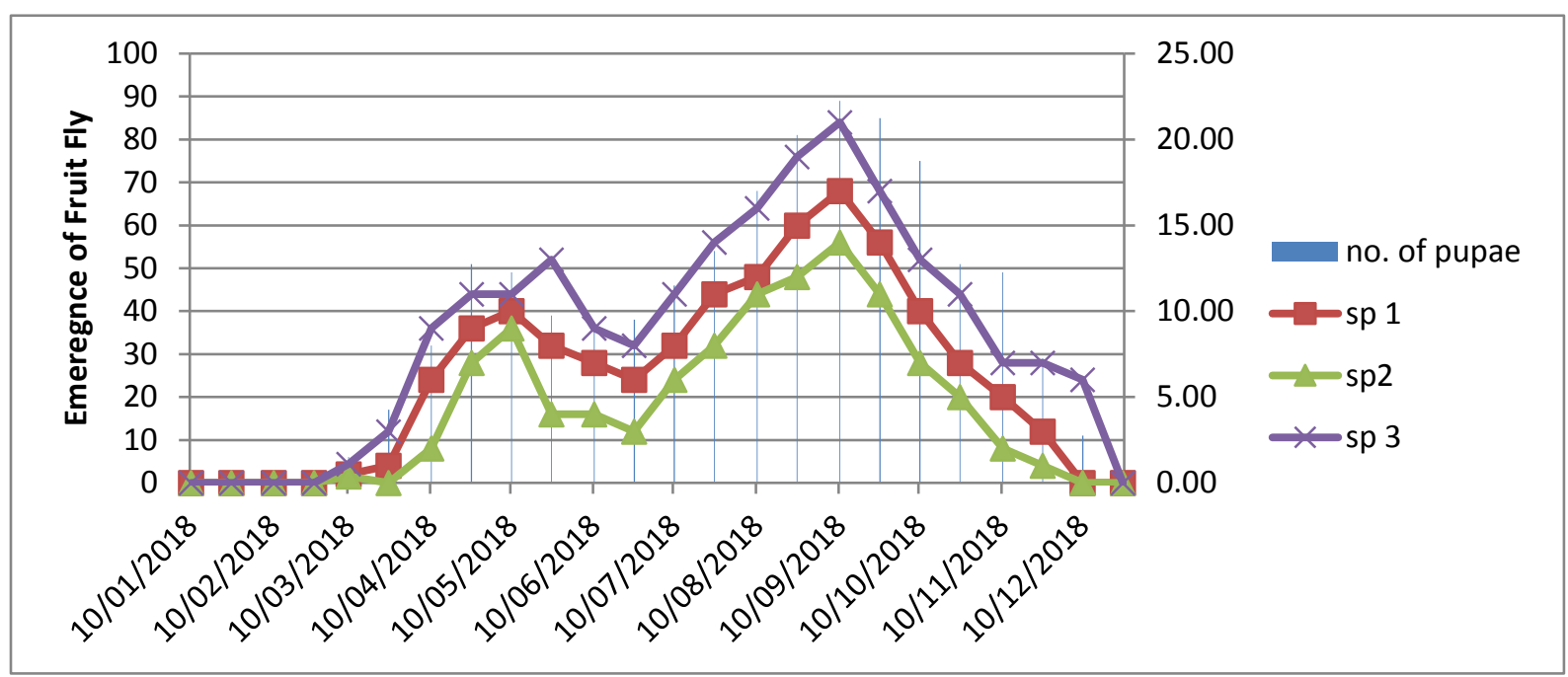

Graph 8.Emergence of different fruitfly species under Laboratory conditions during 2018

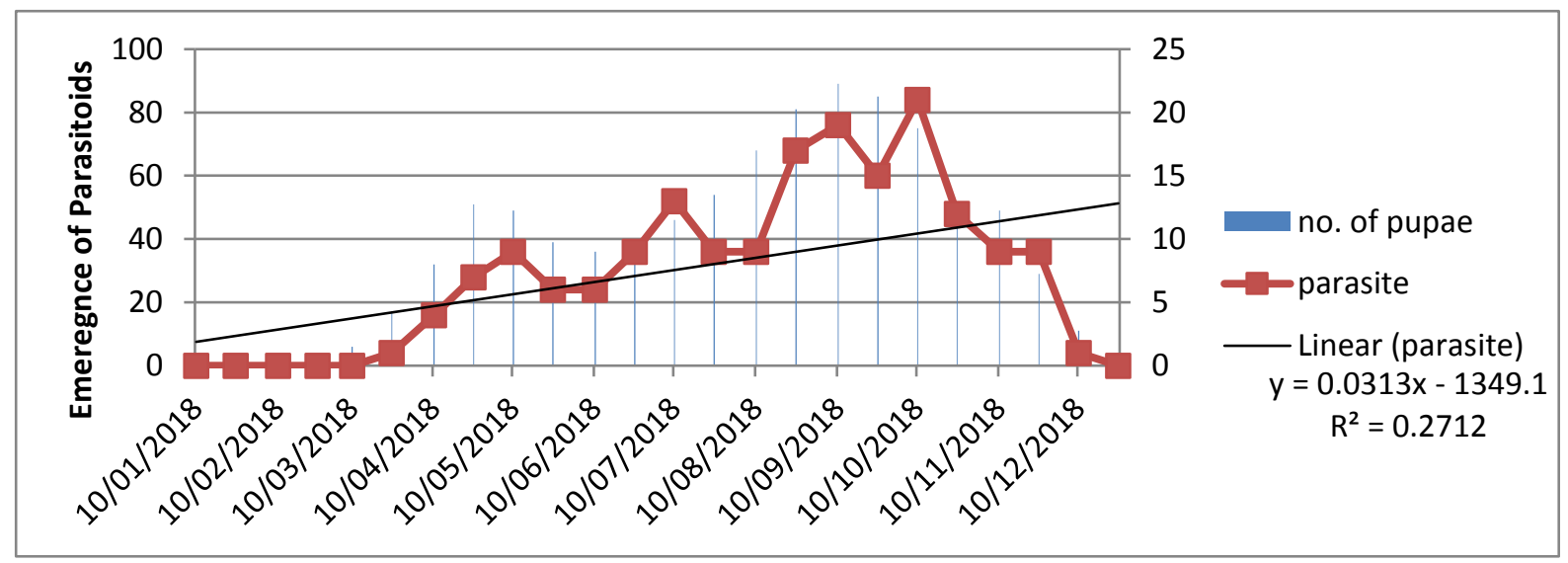

Graph 9. Emergence of parasitoids (Dichasmimorpha longicaudata) under laboratory conditions during 2018 


\section{Discussion}

The Studies on population dynamics of different species of fruit flies (B. zonata, $B$. correcta and $B$. dorsata) and its parasitoid (D. longicaudata) was conducted in district Faisalabad by installing pheromone traps in guava orchards for the period of three years (2016-18).The results of our research indicated that the fruit fly population appeared in March and increased with passage of time and attained highest population peak in October while negligible fruitfly population was observed in December, January and February on guava plants. Our results are similar to researcher who showed that the population of two specie of fruitfly ( $B$. correcta and $B$. dosata) appeared in pheromone traps before April $[31,34]$ and the population gradually increased until end of May but again uplifted to its peak population in August [32,33]. It is also concluded that the fruitfly species $(B$. zonata, B. correcta and $B$. dosata) on guava fruit orchards prevailed throughout the study year. These findings are in accordance with the research who observed fruit fly population throughout the year except in the month of January [19-21]. The variation in Fruit fly species (B. zonata, B. correctaand $B$. dorsata) were also considered in this research. Highest population of $B$. dorsatawas observed during three years of study followed by $B$. zonata and B. correcta. The infested guava fruits were collected from the canopy of fruit trees and kept them under laboratory conditions to identify the fruit fly species and its parasitoid. The pupae of fruit fly emerged from larvae was recorded in April and attained its highest number in October while declined gradually in November and no pupae was observed in December, January and February. From emerging fruit fly, highest number of adults of the B. dorsata was recorded followed by adults of $B$. zonata and $B$. correcta. So it is concluded that Bactorcera dosrsata was found more prominent than other two species. The results are similar to the researchers who revealed the abundance of $B$. dorsalis and B. correcta in many important vegetable crops and different fruits $[22,23$, 30]. The results showed that the population of fruit fly was higher in 2017 then from the previous year but similar population was recorded in 2018 and same pattern was also recorded for number of pupae. The highest parasitoid (D. longicaudata) were observed in July and August. The number of parasitoids directly influenced by the number of pupae emerged from the larvae. The parasitoid was positively affected by the temperature and relative humidity. The results are similar to scientist who indicated that the population of parasitoid and fruit fly population directly influence by relative humidity and temperature [35]. The correlation and regression among the fruit fly population, Parasitoids, Temperature, relative humidity, and rain fall were also worked out. The pest population of all three fruit fly population fluctuation of fruit fly species was significantly positive affected by maximum temperature and relative humidity but the pest population negatively inflicted by low temperature. The results indicated that fruits were more infested by fruit fly in July august and October during 2016-18. These months have high temperature and relative humidity as compared to other months. The researchers also concluded fluctuation in pest population due to maximum and minimum temperatures $[3,24,25]$. The scientist in Lucknow described the similar correlation between pest population and temperature in orchards [37] and the researcher in Karnataka indicated that the fruit fly positively influenced by wind speed in mango orchards [36]. Results indicated that relative humidity played negligible role in fluctuating the pest population. Similar the researcher also concluded that negative correlation of relative humidity with fruit fly population 
[25-27]. In the present study rain fall also slightly affected the pest population adversely. The scientist showed the significant positive correlation between fruitfly and maximum temperature while relatively negative relationship with rainfall and relative humidity [38].

\section{Conclusion}

It is concluded that Bactrocera dorsata remained more abundant than $B$. zonata and $B$. correcta in guava orchard in Faisalabad district during 2016-2018. Pest population varied during whole year. Maximum pest was observed from $2^{\text {nd }}$ fortnight of April to October. Among weather factors, temperature played key role in variation the pest population. The inferred results could predict the maximum infestation periods of fruit flies in guava orchards and help to adopt management practices accordingly.

\section{Authors' Contributions}

Conceived and designed the experiments: KJ Ahmad, Q Ali\&F Hafeez, Performed the experiments: A Aslam, MF Akhtar \& MU Qasim, Analyzed the data: Q Ali, D Hussain \& MJ Saleem, Contributed reagents/materials/analysis tools: MA Ayub \& M Zubair, Wrote the paper: A Aslam, MF Akhtar \& M Shehzad.

\section{References}

1. Hassimotto NM \& Genovese MI (2005). Antioxidant activity of dietary fruits, vegetables, and commercial frozen fruit pulps. J Agric Food Chem 53: 29282935.

2. Lee LWY, Hwang YB, Cheng CC \& Chang JC (1992). Population fluctuation of the melon fly, Dacus cucurbitae, in northeastern Taiwan. Chinese $J$ Entomol 12: 285-292.

3. YE H and Jianhong L (2007). Population dynamics of oriental fruit fly Bactrocera dorsalis (Diptera: Tephritidae) in Xishuangbanna, Yunnan Province, China. Front Agric China 1:76-80.
4. Clarke AR, Allwood A, Chinajariyawong A, Drew RAI, Hengsawad C, Jirasurat M, Krong CK, Kritsaneepaiboon S \& Vijaysegaran S (2001). Seasonal abundance and host use patterns of seven Bactrocera macquart species (Diptera: Tephritidae) in Thailand and Peninsular, Malaysia. Raffles Bull Zool 49: 207-220.

5. Lorscheiter R, Redaelli LR, Botton M \& Pimentel MZ (2012). Damage and larval development of Anastrepha fraterculus (Diptera, Tephritidae) in fruits of two kiwi cultivars (Actinidia spp.) Rev Bras Frutic 34:6776.

6. Montes SMNM, Raga A, Boliani AC \& Santos PC (2011). Population dynamic and occurrence of fruit flies and their parasitoids in peach cultivars (Prunus persica L. Batsch) in presidenteprudente municipality, sp. Rev Bras Frutic 33:402-411.

7. Dhillon MK., Singh R, Naresh JS \& Sharma HC (2005). The melon fruit fly, Bactrocera cucurbitae: A review of its biology and management. J Insect Sci 5: $1-16$.

8. Serem A (2010). Challenges in production and marketing of mangoes in Kenya. In:Unearthing the Gold in Mango Conference, KICC, Nairobi. February 11-12.

9. Duarte RT, Baptista APM, Pazini WC \& Galli JC (2014). Food attractants in the popular monitoring of fruit flies (Diptera: Tephritidae) powder of guava. Nucleus 1:45-53.

10. Dominiak BC, Cagnacci M, Rafferty T \& Barchia I (1998) Field cage release of sterile Queensland fruit fly, Bactrocera tryoni (Froggatt). Gen App Entomol 28: 65-71.

11. Jacobson M (1972). Insect Sex Pheromones. Academic Press, New York. 382. 
12. Makhmoor HD \& Singh ST (1999). Effect of cultural operations on pupal mortality and adult emergence of guava fruit fly, Dacusdorsalis hendel. Ann Plant Prot Sci 7: 33-36.

13. Dashad SS \& Rakesh OPC (1999). Chemical control of ber fruit fly. Crop Res Hisar 17: 333-335.

14. Azevedo FR, Guimarães JA, Simplício AAF \& Santos HR (2010). Population fluctuation and population fluctuation of fruit flies (Diptera: Tephritidae) in commercial guava from the cariricearense region. Arq Inst Biol 77:33-41.

15. Purcell MF (1998). Contribution of biological control to integrated pest management of tephritid fruit flies in tropics and subtropics. Integrated Pest Manag Rev 3:63-83.

16. Purcell MF, Stark JD \& Messing RH (1994). Insecticide effect on three tephritid fruit flies and associated braconid parasitoids in Hawaii. $J$ Econ Entomol 87:1455-1462.

17. Wang XG \& Messing RH (2004). The ectoparasitic pupal parasitoid, (Hymenoptera: Pteromalidae), attacks other primary fruit fly parasitoids: host expansion and potential non-target risk. Biol Control 3:27-236

18. Andleeb S, Shahid MS \& Mehmood R (2010). Biology of Parasitoid Aganaspis daci (Weld) (Hymenoptera: Eucoilidae). Pak J Sci Ind Res 53:201204

19. Gillani W, Tariq B \& Ilyas M (2002). Studies on Population Dynamics of Fruit Flies (Diptera:Tephritidae) in Guava and Nectrin Orchards in Islamabad. Pak J Biol Sci 10.3923: 452.454.

20. Nandre A \& Abhishek S (2014). Population dynamics of fruit fly [Bactrocera dorsalis (Hendle)] on sapota. Agri Sci Dig 34:0976-0547
21. Abro, Zain-Ul-Aabdin, Baloch NA, Khuhro N, Akbar W \& Saeed NA (2017). Population Densities of Melon Fruit Fly Bactrocera cucurbitae (Coquillett) in Vegetables AgroEcosystem in District Hyderabad, Sindh, Pakistan. Sarhad J Agric 33: 331-337.

22. Maung K, Aye K, Lin K, Yin M, Phyu M, Khine, Nyein K, Aye C, Aye P \& Khai (2019). Diversity and abundance of fruit flies (Family: Tephritidae) in Myanmar's tropical region and preliminary prospects for further AWIPM. 7:574-579

23. Morton JG (1987). In: J.F. Morton. Fruits of Warm Climates. Eds. Julia F. Morton and Miami, FL. 356-363.

24. Ganie SA, Khan ZH, Ahangar RA, Bhat HA \& Hussain B (2013). Population dynamics, distribution, and species diversity of fruit flies on cucurbits in Kashmir Valley, India. J Insect Sci13:65.

25. Zaheer ZM, Babar S, Qasim M, Banazeer A, Ansa, Aziz A, KhanM,. Mughal M, Tariq H, Hira, Babar M, Afzal M, Khalid M, Mehmood, Mughal H \& Tariq (2017). Color preferences of fruit flies to methyl eugenol traps, population trend and dominance of fruit fly species in citrus orchards of Sargodha, Pakistan. $J$ Entomol Zool Stu 5:364-368.

26. Nunes MZ, Santos RSS, Boff MIC \& Rosa JM (2013). Evaluation of food attractions in the Anastrepha fraterculus (Wiedemann, 1830) (Diptera: Tephritidae) capture in apple trees. Rev Facultad Agron. 112: 91-96.

27. Rashid k\& Naveed M (2017). Occurrence and Seasonal Abundance of Fruit Fly, Bactrocera zonata Saunders (Diptera: Tephritidae) in Relation to Meteorological Factors. Pak J Zool 49:999-1003.

28. Kapoor VC \& Agarwal ML (1982). Fruit flies and their increasing host plants in 
India. Proc. CEC/IOBC Intern. Symp. Athens/Greece 252-257.

29. Vargas RI, Ramadan M, Hussain T, Mochizuki T, Bautista RC \& Stark JD (2001). Comparative demography of six fruit fly (Diptera: Tephritidae) parasitoids (Hymenoptera: Braconidae). Biol Control 25:30-40.

30. White IM \& Elson-Harris MM (1992). Fruit flies of economic significance: their identification and bionomics. $\mathrm{CAB}$ International, Wallingford. UK, 60.

31. Chen P \& Ye H (2007). Population dynamics of Bactrocera dorsalis (Diptera: Tephritidae) and analysis of factors influencing populations in Baoshanba, Yunnan, China. Entomol Sci 10:141-147.

32. Chen P, Ye H \& Liu J (2006). Population dynamics of Bactrocera dorsalis (Diptera: Tephritidae) and analysis of the factors influencing the population in Ruili, Yunnan Province, China. Acta EcolSinica 26:2801-2808.

33. Mahmood K \& Mishkatullah (2007). Population dynamics of three species of genus Bactrocera (Diptera: Tephritidae: Dacinae) in BARI Chakwal (Punjab). Pak J Zool 39: 123-127.
34. Abbas Q, Hasnain M, Hussain M, Ali Q, Jafir M, Shahid M, Iqbal M, \& Abbas $\mathrm{H}(2018)$. Studies on the population dynamics of fruit flies (Diptera: Tephritidae) on mango orchards in Multan, Punjab, Pakistan. J Pure Appl Agric 3:42-48.

35. Sangvorn K (2000). Seasonal Occurrence of Diachasmimorpha longicaudata (Ashmead) (Hymenoptera: Braconidae), a Parasitoid of Bactrocera correcta (Bezzi) (Diptera: Tephritidae) in a Guava Orchard in Central Thailand. Sci Asia 26:87-92.

36. Verghese A \& Devi KS (1998). Relation between trap catch of $B$. dorsalis and abiotic factors. Proceeding of first national symposium on pest management in horticultural crops. Environmental Implication and Thrusts, Bangalore, India.

37. Mishra J, Singh S, Tripathi A \& Chaube MN (2012). Population dynamics of oriental fruit fly, Bactocera dorsalis (Hendel) in relation to abiotic factor. Hort Flora Res Spect 1:187-189.

38. Kannan M \& Rao NV (2006). Ecological studies on mango fruit fly, Bactrocera dorsalis Hendel. Ann Plant Prot Sci 14:340-342. 